SEES Research Series

Research Article V

\title{
An Investigation into the Level of Preparedness of Artisanal Small-Scale Gold Mining Operations (ASGM) in Mahdia to Transform the Mercury- Free Mining Techniques
}

\author{
Viola King \& Patrick Williams
}

\begin{abstract}
The use of mercury by artisanal small-scale gold miners has resulted in high humanhealth and environmental costs. As a result, mercury usefulness is on the decline to foster more effective and reliable environmentally-friendly alternatives. The artisanal and small-scale gold mining (ASGM) sector contributes significantly as a source of income for thousands of people and a significant source of employment in Guyana. However, extensive uncontrolled mining operations are causing significant environmental, health and socio-cultural problem. The aim of this study was to examine the preparedness of ASGM operations in Mahdia, Guyana in transforming to mercury-free mining technologies. A mixed method approach of both quantitative (questionnaires) and qualitative (interviews) techniques was used for the collection of data. Analysis showed that the majority of the surveyed population was largely unprepared to adopt mercury alternatives, $49 \%$ were somewhat prepared and $30 \%$ were not prepared. While artisanal small-scale gold miners have little knowledge of the dangers of mercury, most believe mercury use to be dangerous. Awareness programmes may help to address reluctance to adopt mercury-free technologies and promote preparedness to phase out mercury in this sector.
\end{abstract}

Keywords: Gold mining, ASGM, mercury, Mahdia

\section{Introduction}

Background

Gold mining is vital to fragile economies in many countries of the world. Artisanal small-scale gold mining (ASGM) usually involves the use of substantial amounts of mercury for mineral extraction (particularly gold), making it the single largest intentional-release of mercury into the world (Vieira, 2004; UNEP, 20I I). Globally, ASGM is estimated to be about 20-30 million miners in more than 55 countries (Spiegel and Veiga, 2009b). At least quarter of the world's total gold supply comes from ASGM; that is approximately 500-800 tonnes per annum (UNEP, n.d.); representing about one third of global mercury consumption, an estimated 650-I,350 tonnes/year with an average of 1000 tonnes, of which $40 \%$ is released into the atmosphere and the remaining $60 \%$ to aquatic systems (Telmer, 2008). This grave misuse of mercury represents about $30 \%$ of 
anthropogenic releases of mercury in the world (Veiga et al., 2005). Although the ASGM sector contributes significantly as a source of income for thousands of persons, extensive uncontrolled mining operations are causing significant environmental, health and socio-cultural problems (Lowe, 2008). Guyana is one of the few countries in the world that have escaped most of the brunt of ecological difficulties being experienced the world over. Nevertheless, Guyana is not insulated from the impending environmental problems (WWF, 2008).

One of the major problems facing the Guianas is the release of mercury from alluvial, colluvial or elluvial gold mining activities. The most popular form of ASGM method is land dredging; a combination of hydraulicking and suction dredging that chiefly relies on mercury. Gold extraction using mercury is conducted in four stages. At each stage mercury is emitted into the environment affecting miners and nearby communities (Vieira, 2004). In response to global effects of mercury contamination of both humans and the environment, the European Union (EU) imposed a ban on the export of mercury in 2010 (Woolford, 2010).

Guyana's economy relies on three main pillars; rice, sugar and gold mining, which replaced the bauxite industry during the 1980s. Gold mining has shown rapid growth since then, with output rising from 17,244 ounces in 1989 to 453,500 ounces in 2002 (Lowe, 2008). In 2010 mining contributed $9 \%$ of GDP and income tax revenue, and accounts for $50 \%$ of foreign exchange earnings (GGMC, 20II). Moreover, 20II was the record year of gold production, which yielded US\$5I7.I million, surpassing the OMAI gold mine highest output of 2004 by $2.5 \%$, and a $49.3 \%$ increase over 2010. This is attributed to an expansion in the ASGM sector, which was spurred by favourable world gold market prices (Kaieteur News, 20I2). The need to ensure the sustainability and viability of mining therefore becomes important to Guyana's development.

Table I: ASGM (Small \& Medium Scale) Gold Production (I997-2009)

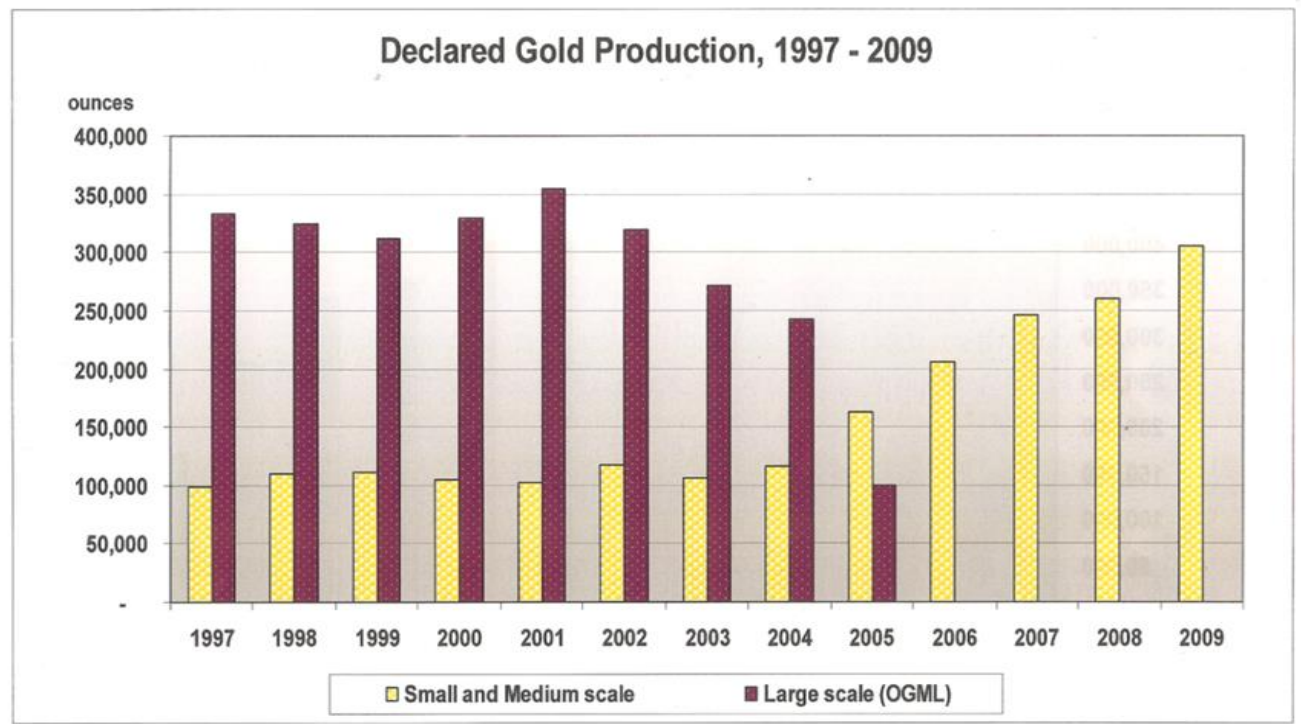

Source: Guyana Geology and Mines Commission (GGMC) 
Table 2: Gold Production of 2008-2010

\begin{tabular}{|c|c|c|c|c|}
\hline Year & Budget (ounces) & Actual (ounces) & Variance & $\%$ Variance \\
\hline 2008 & 230,000 & 260,000 & 30,387 & 13.2 \\
\hline 2009 & 250,000 & 305,178 & 55,178 & 22 \\
\hline 2010 & 300,000 & 308,438 & 8,438 & 2.8 \\
\hline 2011 & 320,000 & - & - & - \\
\hline
\end{tabular}

Table 3: Rank, value and contributions of Guyana exports, 2009 (Source: Clifford, 20I I)

\begin{tabular}{lll}
\hline Export item and ranik & Export value (USS) & \% Contribution (USS) \\
\hline 1. Gold & $281,678,300$ & 36.7 \\
2. Sugar & $119,761,300$ & 15.6 \\
3. Rice & $114,120,100$ & 14.9 \\
4. Bauxite & $79,519,000$ & 10.4 \\
5. Timber & $41,425,000$ & 5.4 \\
9. Diamonds & $14,133,200$ & 1.8 \\
\hline
\end{tabular}

Source: Guyana Bureau of Statistics (2010).

As Guyana is a developing nation, gold mining plays an important role in that it is a major economic contributor to the Gross Domestic Product (GDP). Traditional methods of gold recovery that are still being used are expected to be phased out by 2013 , which can significantly affect the sector. This research assesses the level of preparedness of artisanal miners' in adopting new strategies of gold recovery in light of this transitional period. It highlights the extent to which ASGM operators in Mahdia are willing to reduce mercury use, and subsequently comply with the ban on the metal. The information gathered would then become useful to sector agencies such as the Guyana Geology and Mines Commission (GGMC) and the Guyana Gold and Diamond Miners Association (GGDMA), who can consider measures to remedy issues identified in this work. The advantage of this is that the sector agencies would then have a more proactive approach to issues related to mining. The importance of this research to ASGM should not be overlooked, as it stands to be improved through recommendations of this research, once implemented by the sector agencies. The research objectives were to assess the level of education and awareness of small-scale gold miners of environmentally appropriate gold-mining techniques; and to determine the extent to which the small-scale miners are disposed to adopt alternative gold extraction methods to the use of mercury.

\section{Literature Review}

Generally, the ASGM sector is often characterised by issues of poverty, health, and environmental degradation. This results in unhealthy working conditions and low incomes, which makes it risky to invest in technological capacity. In addition, it is plagued by informal relationships, ambiguous policies and regulations, and the lack of an effective legislative framework (Luz-Dinora Vera et al., 20I2). In 2004, gold production declared by the Guyana Gold Board (GGB) and its licensed dealers reached I16,000 ounces, which represented only two third of total production. It is

\footnotetext{
'For the purpose of this research, a "miner" hereinafter refers to anyone who is directly involved in gold mining operations or activities (e.g. claim owners, dredge owners, and labourers).
} 
believed that one third of all gold produced in Guyana is sold illegally. However, an official stated, there could be many reasons for low production or declaration by some miners, pointing specifically to methods used to recover gold. There are disadvantages of reworking lands due to the presence of mercury powder/flour hence, gold recovery can be low or inefficient (Gordon, 2012; Kaieteur News, 2012).

Mining and mineral processes are often carried out by persons who have little or no knowledge of their environmental impacts and the health hazards associated with poor and irresponsible use of mercury. Over the past decade, several multilateral institutions, NGOs and governments have pledged millions of dollars to address the issues of mercury contamination problems caused by gold miners (Zero Mercury Working Group, 2010; Hilson, 2005). In Colombia where mining is also a dominant economic activity, sustainable mining has improved over the years due to the presence of the Oro Verde (Green Gold) Certification Programme, which involved the use of artisanal mechanisms for separating metals without the use of toxic chemicals; along with other environmental management practices (Luz-Dinora Vera et al., 20I2).

The Oro Verde Programme (OVP) was developed in Choco, Colombia in 2000 and by 2003 the programme completed the certification of 90 family units of production (FUPs) (ibid). By 2004 more than I,600 miners had shown behavioural changes and became aware of the problems associated with mining sector. Between 2005 and 2009 the OVP reached 194 FUPs. The OVP was based on the quality of working conditions for the production of metals and it promotes the conservation and improvement of natural resources; it contributed to community development through, technology transfer; and the establishment of a regulatory framework. All the achievements of the OVP were made possible by community members working in compliance with the ten principles of environmental and social responsibility as well as the criteria adopted by the members of the Oro Verde Certification programme (Luz-Dinora Vera et al., 20I2).

The EU ban on mercury exports began in the year 20II; the US ban on mercury exports begins in the year 2013. Together these countries account for roughly one-third of global mercury supply; causing a notable rise in the price for mercury (UNEP, 2010). However, the literature lacks research on individual countries in analysing environmental education and awareness of mercury-free technologies by ASGM, as well as willingness and/or behavioural changes towards adopting the new technologies. This research will fill the gap by: determining how willing the miners are in the study area to adopt new technologies; and identifying recommendations that can help them in their transition. As such this research is undertaken to specifically determine the extent to which artisanal small-scale gold miners in Mahdia have developed the capability and are willing to adopt alternative technologies to mercury use. 


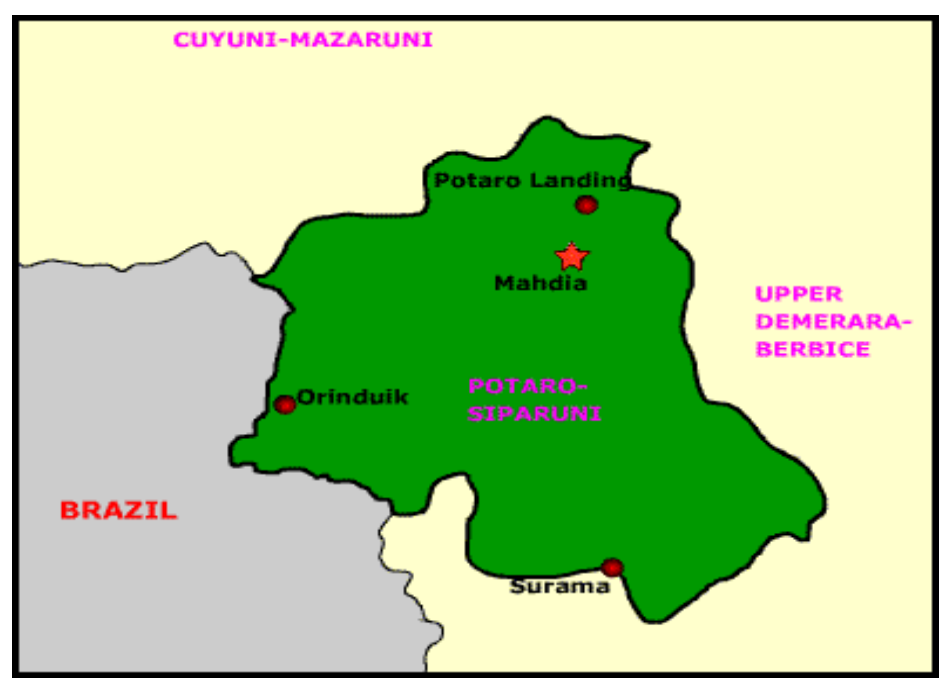

Figure I: Location of Mahdia, Potaro-Siparuni (Region 8)

\section{Overview of Study Area (Mahdia)}

Mahdia is located within the Potaro Mining District of Potaro-Siparuni (Region 8). It is reachable approximately 6 to 7 hours from Georgetown via mini-bus on laterite road; about an hour via small aircraft and by boat from Tumatumari to Garraway Stream, followed by a short road trip (GGDMA, 20II). This area was selected for the research because it is predominantly a mining area of artisanal small-scale gold miners and is fairly accessible. The area also provides an ample amount of mining operations to be sampled so as to obtain sufficient information in order for this study to be effective.

\section{Methodology}

A mixed method approach (quantitative and qualitative methods) was used to gather data. Primary data was collected via field visits (direct observations) and surveys (questionnaires). Secondary data was collected from textual sources such as books, journals, reports, newspapers, and mining reports.

\section{Interviews}

Structured and non-structured interviews were used to gather in-depth information on o the research topic from officers of the GGMC, GGDMA, and members of the Mahdia small-scale gold mining community. The interviews enabled verification of various issues as they arose.

\section{Survey (Questionnaires): Quantitative Approach}

The questionnaire presented a formalised set of questions that were designed to address the research objectives and questions. It was used to collect data from gold miners in the study area, and was administered in person so that respondents could clarify questions as needed.

\section{Field Visit}

A field visit was carried out in April 2012 to conduct field samples (questionnaires), interviews, and to acquire first-hand experience of the various gold mining procedures used by artisanal and small-scale gold miners; as well as the environmental issues associated with these processes. 
Sampling Technique

The type of sample used for this research was the simple random sampling approach; which enabled each individual or mining operation in the tangent population of Mahdia to have a probability of being sampled. An officer of the Land Management/Cartography Department at GGMC indicated that there were 175 legal gold mining operations (land dredges) in Mahdia.

The formula for the representative sample is as follows:

Confidence level 95\%; Confidence interval 5\%

The sample size is determined by:

$\mathrm{SE}=$ standard error (confidence interval) $=5 \%$

$\mathrm{N}=$ (population; total number of registered dredges) $=175$

Therefore,

$$
\mathrm{n}=\frac{175}{1+175(0.05) 2}=\frac{175}{1.4375} \quad \underline{\mathbf{1 2 1 . 7}}
$$

Only eighty (80) questionnaires were administered, for reasons listed in the study limitations.

\section{Ethical Considerations}

The researcher informed the relevant authorities/interviewees from GGMC and GGDMA beforehand of research activities in order to solicit their participation. Before the field visit, the researcher requested permission from the GGMC Office in Mahdia, through the GGDMA office, Georgetown. This was done in order for the researcher to have accommodation, transportation and assistance within the Mahdia community and infield data collection. In addition, miners were assured that all information provided was treated with the highest level of confidence in order to protect their identity.

\section{Data Analysis}

The data collected was analysed using multiple approaches. Data from the questionnaires are represented in the form of tables, bar-graphs, pie charts using Microsoft Excel and inferential analysis was conducted using the SPSS software. Interviews conducted with key stakeholders were analysed and inferences drawn from the data obtained from questionnaires and other survey instruments.

\section{Limitations}

- The spatial distribution of mining operations in the area influenced the number of samples.

- The research was bounded; as such limits were placed on the extent of the time/duration period of the surveys in order to complete the survey in time.

- Information from the water dredge miners was inaccessible; they mostly comprised Brazilian miners, which presented a communication issue and limited administration of the questionnaire. 


\section{Analysis and Discussion}

\section{Socio-economic Details}

All of the information gathered were from land dredge operations; with labourers being the highest (39.8\%), followed by dredge owners (22.6\%), and dredge managers (I7.2\%). It should be noted that some of the dredge owners were claim owners and managers. Of the total respondents, $81.2 \%$ depended directly on their mining operations for income; while $18.8 \%$ worked other jobs such as logging (3.8\%), farming (3.8\%), and other activities such as carpentry and transportation services (II.2\%).

Most miners had attained primary education (56.2\%), while $27.5 \%$ attained secondary education. A combined total (81.3\%) of miners lived outside of Mahdia in areas such as Georgetown and Berbice; whereas, $11.2 \%$ of respondents lived at Mahdia.

Objective One: Assessment of education and awareness of small-scale gold miners of environmentally appropriate gold-mining techniques

Most respondents had little or no knowledge of the proposed ban on mercury, while $46 \%$ were somewhat aware of the ban on the mercury. Respondents stated that they had heard about the mercury ban from friends, while $20 \%$ were not aware of the ban at all. All of the respondents used mercury in their operations, with the majority (37.5\%) using 3-4 ounces per amalgamation while $30 \%$ used more than nine ounces but less than two pounds per amalgamation (also known as 'washdown').

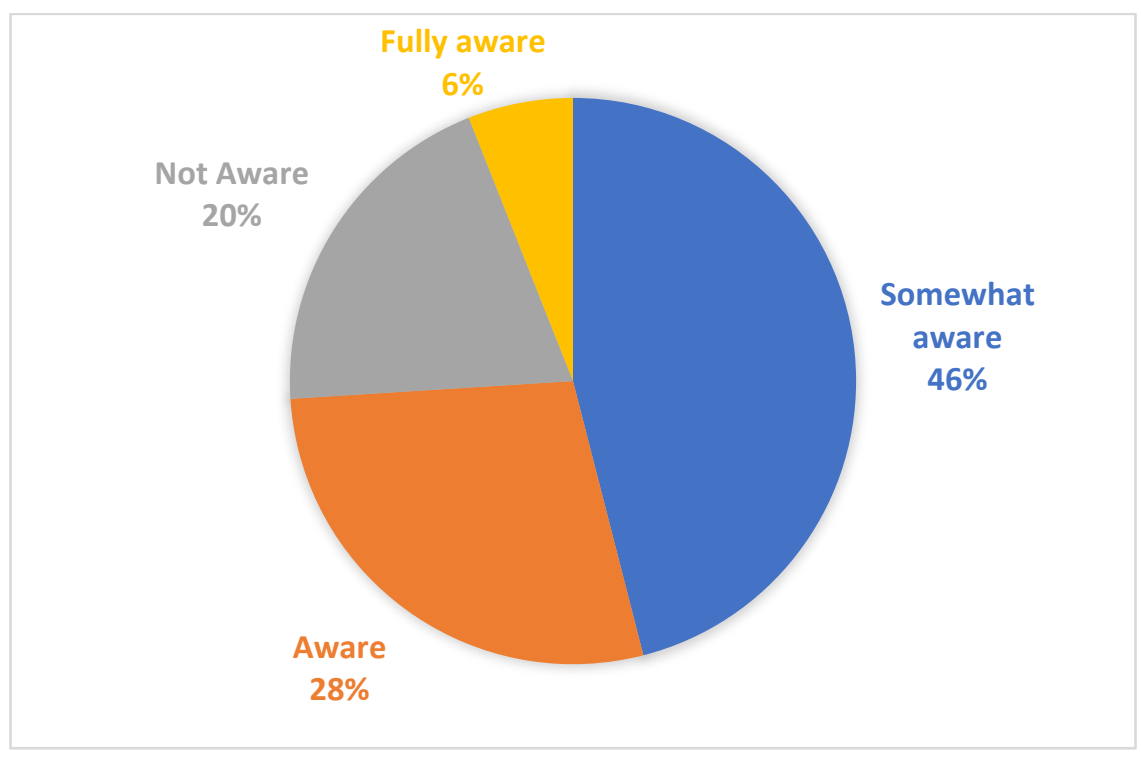

Figure 2: Miners' awareness of imposed mercury ban

In assessing the knowledge bases of mercury and its proposed alternatives, it was found that even though $92.5 \%$ believed mercury to be dangerous, $31.2 \%$ did not know that the improper use and storage of mercury could be dangerous to their health and the environment. Moreover, $21.2 \%$ knew about mercury poisoning but more than half of respondents did not know the symptoms associated with mercury poisoning, as the majority listed malaria and dengue symptoms instead. 
The GGMC has developed several tools and initiatives, formulated in compliance with the Guyana's Low Carbon Development Strategy (LCDS), to enhance the levels of performance and compliance in the mining sector toward its 2015 goal of reduction in emissions from deforestation and forest degradation. One such initiative is the "applied research and field demonstration for improved gold recovery without mercury use" (GGMC, 20I0). A senior official from GGMC explained that in each mining district, Mines Officers are responsible for informing the artisanal small-scale gold miners of the alternatives and providing demonstration sessions where necessary. However, findings from this study showed that $93.8 \%$ of respondents were unaware of mercuryfree alternative technologies, and $90 \%$ had not received information from the relevant authorities. In addition, no respondent had received training on the use of mercury-free technologies. This may be due, in part, to lack of information dissemination among authorities and respondents; and among the dredge owners/managers and their workers.

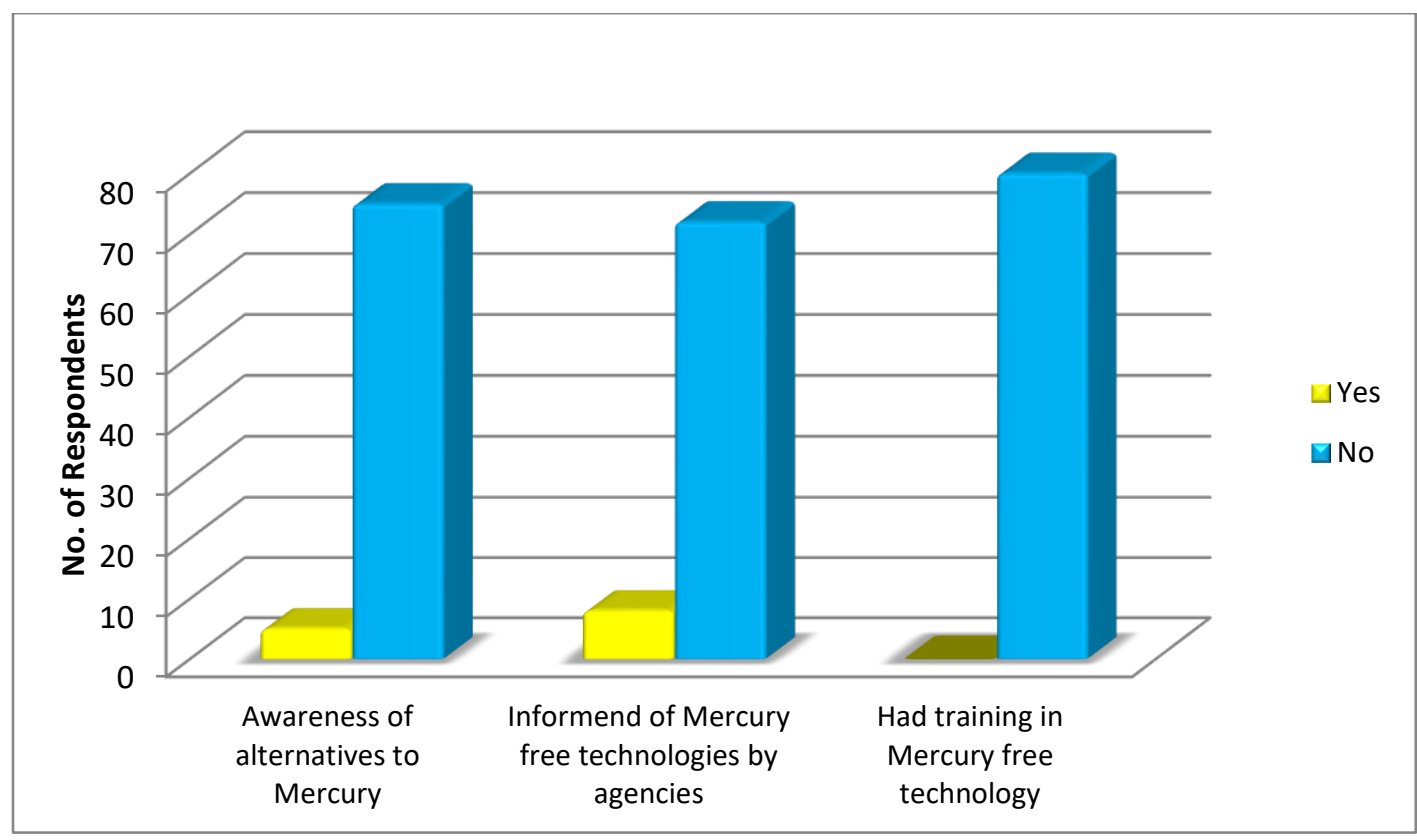

Figure 3: Knowledge and Training of Alternatives to Mercury

Further, an official from the GGDMA elaborated that the average miner did not know about mercury-free technologies and the mercury abatement/ban. He indicated that it is a difficult task in getting small miners to adopt new procedures, especially when considering cost factors. During the demonstration session held in Georgetown (20II), a GGMC official said there were miners who showed some interest in the new technologies, but most were concerned about the price, which they said was too expensive. In addition, the GGDMA official believed that greater attention should be focused on mercury alternatives rather than the technologies, which are very costly and still require the use of mercury at the final stage to produce gold sponge or bullion.

Respondents were also asked why they were not trained or informed about the alternatives. Responses included: "We are trying to make a living, and we ain't got the time and money to travel to Georgetown for the mining meeting." Mining workshops and other awareness programmes facilitated by the GGMC and other agencies are usually held in the capital city, one to three times per year. The respondents further stated that only the "boss man" (i.e. the dredge 
owner or camp manager) attends these programmes, who returns to the work site to collect their gold. They reportedly do not inform workers of education and awareness programmes that may have been conducted. As a result, respondents remain unaware of mercury-free technologies and the importance of such technologies.

During an interview with the Mines Officer in Mahdia, he concurred with the finding that miners in the area were never trained and said no training or demonstration was done in the district. He added that a shaking table was set up on a miner's claim for him to experiment for himself and to eventually show other miners of its efficiency and the know-how. This was done mainly because the Commission did not want to employ persons to work (demonstrate) on or encroach upon miners' claims, hence inconveniencing miners' work activities. He added that the majority of miners also prefer to 'see things in action'; i.e., they have to work with the technology/equipment and develop the expertise and have first-hand experience with the technology. In this way, miners would be more motivated to adopt alternatives.

Objective Two: Determining extent to which small-scale miners were willing to adopt mercury alternative gold extraction methods.

Respondents were found to be largely unprepared to adopt mercury alternatives, as $49 \%$ were somewhat prepared and $30 \%$ were not prepared. When asked what factors would motivate them to switch or to implement mercury-free methods in the operations, various responses were given such as: assurance that mercury-free methods have a higher recovery rate than that of mercury use; the fact that mercury is dangerous to health; education and training available on how to use the mercury-free technologies, and whether the alternatives are affordable and accessible. Nevertheless, $65 \%$ of respondents saw the need to implement mercury-free alternatives given that mercury is dangerous. Among the respondents who saw the need to implement alternatives, persons indicated they were fully prepared (4\%), prepared (17\%), or somewhat prepared (49\%); while $21.2 \%$ felt unprepared. 
Table 4: The need for Hg alternatives * Gold miner preparedness to adopt mercury free technologies (Cross tabulation)

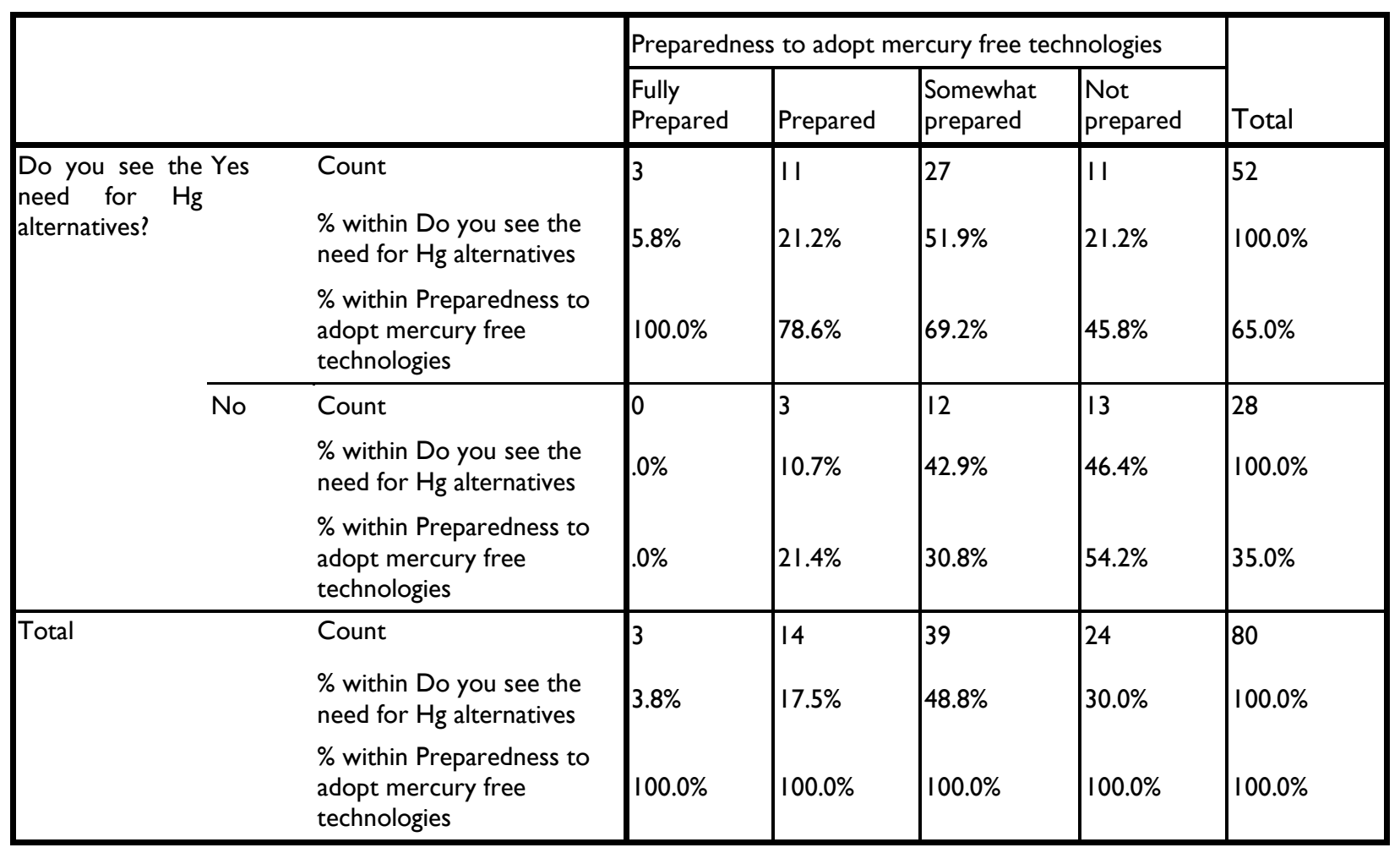

The Mining (Amendment) Regulations 2005 specified the use of safety equipment such as a retort, gloves, and respirator. Yet $72.2 \%$ of respondents did not use protective gear, mainly because they are not accessible (39\%), not accustomed to wearing it (39\%), or find them uncomfortable (I8\%). On the other hand, respondents indicated they would be more willing to use such equipment should the technologies have greater recovery rates than that of mercury.

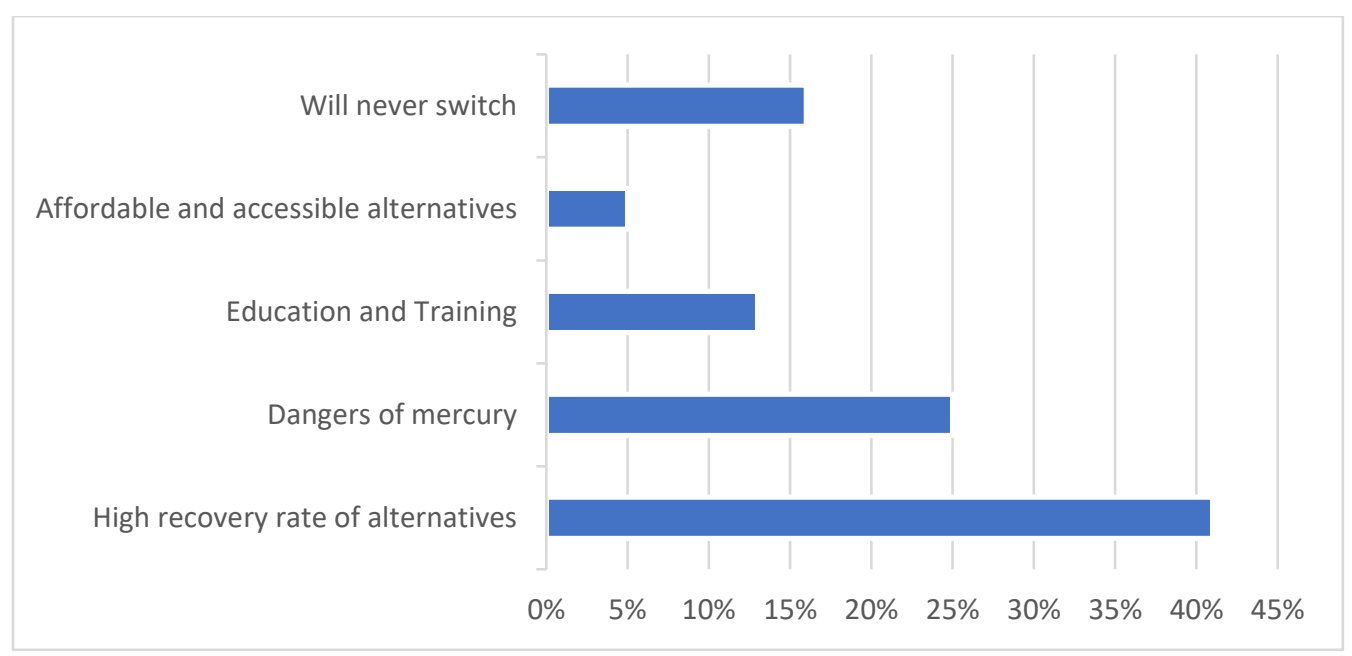

Figure 4: Factors influencing miners' use of mercury-free technologies 


\section{Conclusion}

Environmentally-appropriate gold mining techniques are extremely important to sustain Guyana's economy. From this study, 93.8\% of respondents at Mahdia were unaware of mercury-free technologies, and none of them had been trained to use these technologies. This was mainly because most, if not all, of training and awareness programmes on mercury-free technologies were being held in Georgetown rather than in mining areas. Many were also unaware of the impact of mercury on their health and the environment. Respondents were also found to be largely unprepared to adopt mercury alternatives, as $49 \%$ indicated they were somewhat prepared and $30 \%$ were not prepared at all. While respondents knew that mercury is dangerous, they didn't understand the extent of the danger or the consequences of mercury contamination. It was found that not knowing this may have contributed to miners' reluctance to adopt mercuryfree technologies.

The elimination of mercury from the EU and US markets and the subsequent high price of the metal will likely hasten the adoption of mercury-free alternatives in ASGM processes (Balistreri \& Worley, 2009). However, artisanal and small-scale gold miners need to appreciate that mercury-free technologies can generate more profit and improve gold recovery, while protecting their health and the terrestrial and aquatic environment. This can provide positive outcomes for both economic development and environmental protection. Several recommendations emerge from this study:

I. Plausible and cheaper alternatives to mercury use need to be available before the implementation of the mercury ban in Guyana.

2. Greater education and awareness campaigns are needed about the ban on mercury and the dangers of the poisonous substance.

3. Authorities should also provide awareness programmes for community members on safer mining practices, since their livelihoods can be affected by current practices.

4. One solution is for the GGMC to establish a facility to process gold miners' concentrate. However the process must be transparent to secure the confidence of artisanal smallscale gold miners.

5. More advocacy and demonstrations are needed by the GGDMA to promote alternative technologies.

6. Government and relevant authorities should work towards promoting alternatives to mercury such as borax. ${ }^{2}$ As mercury-free technologies are expensive, it is difficult for ASGM to adopt; and even if they do adopt them, some amount of mercury will still be used at the final stage in their mining operation. Borax on the other hand, is more efficient, affordable and will eliminate the poisonous substance mercury completely.

7. The regulatory agency and sector agencies should assist in capacity development and technology transfer to facilitate introduction of mercury-free mining methods.

8. The Environmental Protection Agency, Guyana Gold Board, and Guyana Forestry Commission should play a more integral role in monitoring and enforcement within the mining sector and ease the overwhelming responsibilities placed on the GGMC. This will foster a more comprehensive regulatory body and improve monitoring and enforcement.

9. A feasibility study should be done in order to assess the consequent implementation of the mercury ban on the local mining industry.

\footnotetext{
${ }^{2}$ Borax is natural mineral, a common household and commercial chemical with a chemical formula $\mathrm{Na} 2 \mathrm{~B} 4 \mathrm{O} 7 \cdot 1 \mathrm{OH} 2 \mathrm{O}$. Borax is
} also known as sodium borate, sodium tetraborate or disodium tetraborate. 


\section{Acknowledgements}

Sincere thanks are extended to the study participants and those who facilitated travel to Mahdia and the mining sites.

\section{References}

Balistreri, E.J. and Worley, C.M., 2009. Mercury: The good, the bad, and the export ban. USA: Elsevier Ltd.

Clifford, M.J., 20 I I. Pork knocking in the land of many waters: Artisanal and small-scale mining (ASGM) in Guyana. UK: Elsevier Ltd.

GGMC, 20I I. Guyana Geology and Mines Commission Mining Supplement.

Gordon, A., 2012. Guyana Times News: Plan in train to tackle gold smuggling - Persaud. Available at: $<$ http://www.guyanatimesgy.com/20 12/05/22/plan-in-train-to-tackle-gold-smugglingpersaud/>

Hilson, G., 2005. Abatement of mercury pollution in the small-scale gold mining industry: Restructuring the policy and research agendas. Wales, UK: Elsevier Ltd.

Kaieteur News, 2012. "Guyana, Suriname collaborating on illegal gold trade”. Available at: <http://www.kaieteurnewsonline.com/2012/06/2 I/guyana-suriname-collaborating-onillegal-gold-trade/>

Lowe, S., 2008. Situation analysis of the small-scale gold mining sector in Guyana. WWF, Guianas Program.

Low Carbon Development Strategy, 2010. Office of the President, Republic of Guyana. Available at: < http://www.lcds.gov.gy/>

Luz-Dinora, V., et al., 2012, Community-building and green cold certification: The experience of the Oro Verde, Colombia. Canada: HEC Montreal.

Module 3: Mercury Use in Artisanal and Small-sale Gold Mining. Available at: <http://www.chem.unep.ch/mercury/awareness_raising_package/E_0I-I6_BD.pdf>.

20I I. THE SHOUT - The Magazine of the Guyana Gold and Diamond Miners Association. Georgetown, Guyana: GGDMA

Spiegel, S. and Veiga, M., 2009. International guidelines on mercury in small-scale gold mining Canada: Elsevier Ltd.

Telmer, K., 2008. World emission of mercury from small scale artisanal gold mining and the knowledge gaps about them. Canada: University of Victoria. 
United Nations Environmental Programme [UNEP], n.d. Module 3: Mercury Use in Artisanal and Small-scale Gold Mining. Available at:

<http://www.chem.unep.ch/mercury/awareness_raising_package/E_0I - I6_BD.pdf>.

United Nations Environmental Programme [UNEP], 2010. Artisanal and small scale gold mining and mercury pollution. Available at:

<http://www.unep.org/hazardoussubstances/Portals/9/Mercury/Documents/ASGM/All\%2 OPresentations\%20from\%20WB-UNEP\%20Dar\%20meeting\%200ct\%2020I0.pdf>.

Veiga, M.M, et al., 2005. Pilot project for the reduction of mercury contamination resulting from artisanal gold mining fields in the Manica District of Mozambique: Final report. New York: Blacksmith Institute. Available at: <http://www.globalmercuryproject.org/countries/mozambique/docs/Moz_Final_Report_ Aug_2005.pdf>

Vieira, R., 2004. Mercury-free gold mining technologies: possibilities for adoption in the Guianas. Suriname: WWF Guianas. Available at: <http://www.globalmercuryproject.org/database/Upload/Guianas\%202005\%20Vieira\%20 $\mathrm{Hg} \% 20$ free\%20techniques.pdf>

Woolford, W., 2010. Mining sector ponders alternative methods of gold recovery. Stabroek News, 12 March. Available at: <http://www.stabroeknews.com/2010/business/03//2/as-deadlinesnear-for-us-eu-bans-on-mercury-exports\%E2\%80\%A6/>

World Wildlife Fund, 2008._Environmental conservation in Guyana. Guyana: WWF Guianas.

Zero Mercury Working Group, 20 I0. Training of trainers on alternatives of mercury and best available techniques (BATs) and best environmental practices (BEPs) in artisanal and small scale mining in Tanzania (Phase III). Available at: <http://www.zeromercury.org/phocadownload/Whats_on_in_the_regions/ASGM_Bora x_Training_Report-20102.pdf> 